\section{Lord's paradox in latent change score modeling: an example involving facilitating longitudinal effects between intelligence and academic achievement}

\author{
Kimmo Sorjonen ${ }^{1}$, Bo Melin ${ }^{1}$, \\ \& Gustav Nilsonne ${ }^{1,2}$
}

\author{
${ }^{1}$ Department of Clinical Neuroscience, Karolinska \\ Institutet, Stockholm, Sweden \\ ${ }^{2}$ Department of Psychology, Stockholm University, \\ Stockholm, Sweden
}

\section{Abstract}

It has been claimed that intelligence causes academic achievement to increase over time, and that also, conversely, academic achievement causes intelligence to increase over time. This bidirectional facilitating longitudinal effect between intelligence and academic achievement rests on observed associations between initial intelligence and the change in academic achievement between an initial and a subsequent measurement, and vice versa. Here, we demonstrate, through simulating empirical data used in previous research, that such longitudinal associations may be due to regression toward the mean rather than a true facilitating effect. Regression toward the mean occurs due to the conditioning of change on the initial value on the outcome variable. Researchers should be aware of this fallacy and are recommended to verify their findings with analyses without adjustment for an initial value on the outcome.

Keywords: academic achievement, facilitation, intelligence, longitudinal data, re-analyses, regression toward the mean, simulation, spurious association

\section{Introduction}

Assume an association between a variable $\mathrm{X}$ and the true value on another variable $\mathrm{Y}$, and that $\mathrm{Y}$ is measured with some degree of error. Given these conditions, even if no true change in $\mathrm{Y}$ has taken place, we will tend to see an association between $\mathrm{X}$ and the observed value on $\mathrm{Y}$ at a subsequent measurement, or the change in $\mathrm{Y}$ between an initial and a subsequent measurement, if we adjust for the observed value on $\mathrm{Y}$ at the initial measurement (Castro-Schilo \& Grimm, 2018; Eriksson \& Häggström, 2014; Glymour et al., 2005; Sorjonen et al., 2019, 2021). The reason for this spurious association is that given the same initial value on $\mathrm{Y}$ and a positive association between $\mathrm{X}$ and the true value on $\mathrm{Y}$ we can assume a negative association between $\mathrm{X}$ and the residual, i.e. measurement error, in $\mathrm{Y}$ at the initial measurement. And as measurement errors tend to regress toward a mean value of zero, we should expect a more positive change in $\mathrm{Y}$ from the initial to the subsequent measurement for those with a high value on $X$ compared with those with the same initial value on $\mathrm{Y}$ but with a lower value on $\mathrm{X}$. As an example, if an Olympian long jumper and a random person from the street jump equally long on an initial jump, we should assume that the Olympian has performed further from her true ability and that she, consequently, will increase more to the next jump compared with the person from the street.

Intelligence and academic achievement tend to be positively associated (Deary et al., 2007; Peng et al., 2019; Roth et al., 2015) and we should probably assume that both measured intelligence and academic achievement are less than perfect indicators of true abilities. Consequently, if two individuals with high and low intelligence, respectively, exhibit the same academic achievement, we should assume a more negative residual for the former and expect, due to regression toward the mean, a larger improvement, alternatively a smaller deterioration, to a subsequent measurement for the person with high intelligence. Similarly, if conditioning on initial measured intelligence, we should expect a more positive change in intelligence to a subsequent measurement for those with high academic achievement compared with those with lower academic achievement.

These predictions are based on regression toward the mean (Galton, 1886) and do not require any change in true intelligence or academic ability. However, if not conditioning on the initial value on the outcome variable, we would probably not expect any association between intelligence and the residual in the measurement of academic achievement or between academic achievement and the residual in the measurement of intelligence. Therefore, compared with adjusted effects, unadjusted effects of a predictor, e.g. intelligence, on a change score on the dependent variable, e.g. academic achievement, tend to be less affected by regression toward the mean and give less biased estimates of the true association between the predictor and change on the dependent variable. At least this can be expected if there is, as in our example, an association between the predictor and the general level of the dependent variable and if the dependent variable is measured with error (CastroSchilo \& Grimm, 2018; Eriksson \& Häggström, 2014; Glymour et al., 2005; Sorjonen et al., 2019, 2021).

Studies have found a positive association between intelligence and subsequent academic achievement, e.g. grades and standardized test scores, or between intelligence and change in academic achievement between two measurements, when adjusting for academic achievement measured at an earlier occasion, and this has been suggested to indicate that intelligence promotes a positive development in, or is a temporal precursor of, 
academic achievement (Lechner et al., 2019; Saß et al., 2021; Watkins et al., 2007; Watkins \& Styck, 2017). Similarly, a positive association between academic achievement and a subsequent intelligence score while adjusting for an earlier measurement of intelligence has been proposed to demonstrate that academic achievement facilitates a positive development in intelligence (Peng et al., 2019; Saß et al., 2021).

The objective of the present study was to evaluate the credibility of the above claims about facilitating longitudinal effects between intelligence and academic achievement. If intelligence and academic achievement truly facilitate each other's longitudinal development, we should be able to observe: (1) A positive association between intelligence (academic achievement) and change in academic achievement (intelligence) both when adjusting and when not adjusting for initial academic achievement (intelligence); (2) A negative effect of intelligence (academic achievement) on the backward change in academic achievement (intelligence), from the subsequent to the initial measurement, when adjusting for subsequent academic achievement (intelligence). This latter negative effect would indicate that given the same academic achievement (intelligence) at the subsequent measurement, those with higher intelligence (academic achievement) tended to have a lower score at the initial measurement but now they have caught up with those who had higher initial academic achievement (intelligence) but lower intelligence (academic achievement). These predictions were evaluated in data simulating the data used by Lechner et al. (2019) and by $\mathrm{Saß}$ et al. (2021). A failure to meet the predictions would indicate that the observed associations may be spurious and due to regression toward the mean rather than due to true facilitating effects between intelligence and academic achievement.
Method

We used simulated data to investigate observed effects in latent change score models. As results of latent change score models depend on mean values and correlations in data, simulated data with known means and correlations are fully sufficient to reproduce model behavior, while having the added advantage that they can be shared fully openly. We therefore created datasets with the same sample sizes, means, standard deviations, and correlations between variables as in the data used by Lechner et al. (2019) and by Saß et al. (2021). We refer to the original papers for more information on the samples, used measures, and conducted analyses. In short, Lechner et al. used data from German students ( $N$ $=4646,51 \%$ male) who were, on average, 12.9 years old $(S D=0.5)$ at the initial measurement of academic achievement and with an interval of approximately 2 years between the measurements. Academic achievement was measured with standardized tests, consisting of 23-30 items, of reading and math competence. Composite scores were calculated based on item response theory. Intelligence was measured with matrices tests, with three set scores used as indicators of a latent intelligence factor. Intelligence was measured only once, approximately 2 years prior to the first measurement of academic achievement, i.e. at approximately 11 years of age.

$\mathrm{Sa}$ et al. used data from 6 separate samples of $10-15$ years old German students $(N=1597,9864$, 9988, 1032, 1355, and 992, respectively; percent male $=50,50,49,50,53$, and 49, respectively). The time interval between measurements was approximately $0.75,4,1,2,2$, and 2 years in the six samples, respectively. In each sample, academic achievement was measured both with standardized tests and with grades in reading and math. In samples 2, 4, 5, and 6, intelligence was measured with a shortened German adaptation of the Culture
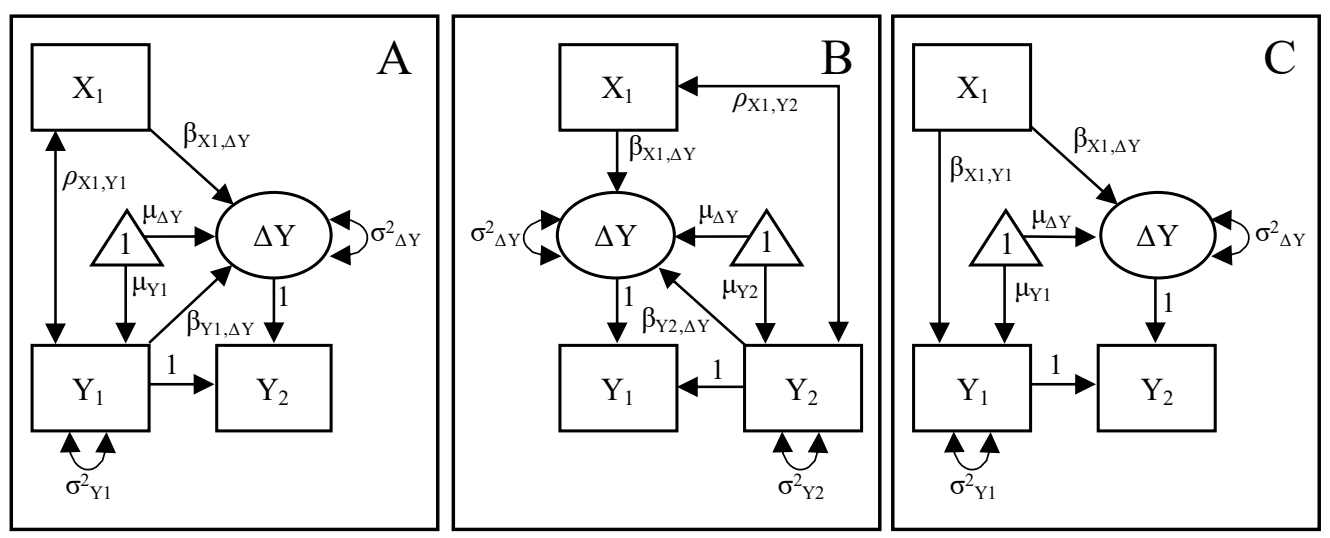

Figure 1. Latent change score models where forward change in $\mathrm{Y}$ is regressed on the initial value on $\mathrm{X}$ and with adjustment for the initial value on $\mathrm{Y}(\mathrm{A})$, backward change in $\mathrm{Y}$ is regressed on the initial value on $\mathrm{X}$ and with adjustment for the subsequent value on $\mathrm{Y}(\mathrm{B})$, and forward change in $\mathrm{Y}$ is regressed on the initial value on $\mathrm{X}$ without adjustment for the initial value on $\mathrm{Y}(\mathrm{C})$. 
Fair Intelligence Test, where the number of correct responses on 46 multiple choice items were summed. In samples 1 and 3, intelligence was measured with 25 items from a German version of the Cognitive Ability Test. In all six samples, both academic achievement and intelligence were measured on both occasions.

\section{Statistical analyses}

In accordance with Lechner et al. (2019), we employed latent change score modeling (Ghisletta \& McArdle, 2012; Kievit et al., 2018; McArdle, 2009). In forward predictions (Figure 1, panel A), the subsequent value on the outcome variable $\left(\mathrm{Y}_{2}\right)$ was predicted from the initial value and a latent change factor. Both regression weights were fixed to 1, i.e. $\mathrm{Y}_{2}$ was predicted to equal $\mathrm{Y}_{1}+\Delta \mathrm{Y}$ and $\Delta \mathrm{Y}$ was, consequently, defined as $\mathrm{Y}_{2}-\mathrm{Y}_{1}$. The intercepts (triangle in the figure) and error variances (curved double-headed arrow) of $\mathrm{Y}_{1}$ and $\Delta \mathrm{Y}$ were freely estimated while they were fixed to zero for $\mathrm{Y}_{2}$, meaning that $\mathrm{Y}_{2}$ was fully defined by $\mathrm{Y}_{1}$ and $\Delta \mathrm{Y}$, and predicted to be zero if both $\mathrm{Y}_{1}$ and $\Delta \mathrm{Y}$ were zero. $\Delta \mathrm{Y}$ was regressed on $\mathrm{Y}_{1}$ in addition to $\mathrm{X}_{1}$, and $\mathrm{Y}_{1}$ and $\mathrm{X}_{1}$ were allowed to correlate (Figure 1, panel A). However, we also conducted analyses where $Y_{1}$ and $\mathrm{Y}_{2}$ changed places, in which case the latent change score $\Delta Y$ captured increase backward in time, i.e. how much $\mathrm{Y}$ had decreased from the initial to the subsequent measurement (Figure 1, panel B). We also conducted analyses where $\Delta \mathrm{Y}$ was regressed on $X_{1}$ but not on $Y_{1}$, and $Y_{1}$ was regressed on $\mathrm{X}_{1}$ (Figure 1, panel C). In the re-analyses of data resembling those used by Lechner et al., $\mathrm{X}_{1}$ equaled a latent intelligence factor and $\mathrm{Y}$ equaled reading and math competence, respectively. In the reanalyses of data resembling those used by $\mathrm{Sa}$ et al., $\mathrm{X}_{1}$ was initial intelligence and $\mathrm{Y}$ was either math score, math grades, reading score, or reading grades measured at two occasions, respectively, or vice versa. Analyses were conducted with $\mathrm{R}$ 4.1.0 statistical software (R Core Team, 2021), employing the packages lavaan (Rosseel, 2012), MASS (Venables \& Ripley, 2002), and weights (Pasek,

Table 1. Standardized regression effects of initial intelligence $(g)$ and academic achievement (aa) on each other's change between two measurements. Separately for latent change score models with forward prediction and adjustment for the initial value on the outcome (Forw.), with backward prediction and adjustment for the subsequent value on the outcome (Back.), and forward prediction without adjustment for the initial value on the outcome (Nonadj.).

\begin{tabular}{|c|c|c|c|c|c|c|c|}
\hline \multirow[b]{2}{*}{ Sample } & \multirow[b]{2}{*}{ aa } & \multicolumn{3}{|c|}{$g_{1} \rightarrow \Delta \mathrm{aa}^{1}$} & \multicolumn{3}{|c|}{$\mathrm{aa}_{1} \rightarrow \Delta g^{2}$} \\
\hline & & 1.Forw. & 2.Back. & 3.Non-adj. & 4.Forw. & 5.Back. & 6.Non-adj. \\
\hline L. $2019^{3}$ & $\mathrm{~ms}^{5}$ & $0.281 * *$ & $0.438 * *$ & $-0.226^{* *}$ & - & - & - \\
\hline L. $2019^{3}$ & $r s^{6}$ & $0.203 * *$ & $0.322 * *$ & $-0.614 * *$ & - & - & - \\
\hline \multicolumn{8}{|l|}{ S. $2021^{4}$} \\
\hline sample 1 & $\mathrm{~ms}^{5}$ & $0.221 * *$ & $0.321 * *$ & $-0.095 * *$ & $0.334 * *$ & $0.363 * *$ & $-0.067 *$ \\
\hline sample 1 & $\mathrm{mg}^{7}$ & $0.203 * *$ & $0.226 * *$ & -0.019 & $0.170 * *$ & $0.185 * *$ & -0.044 \\
\hline sample 1 & $\mathrm{rs}^{6}$ & $0.255^{* *}$ & $0.313 * *$ & -0.021 & $0.272 * *$ & $0.326 * *$ & $-0.075 *$ \\
\hline sample 1 & $\mathrm{rg}^{8}$ & $0.121 * *$ & $0.201 * *$ & $-0.050^{*}$ & $0.128 * *$ & $0.165 * *$ & $-0.052 *$ \\
\hline sample 2 & $\mathrm{~ms}^{5}$ & $0.252 * *$ & $0.356 * *$ & $-0.115 * *$ & $0.262 * *$ & $0.367 * *$ & $-0.062 * *$ \\
\hline sample 2 & $\mathrm{mg}^{7}$ & $0.153 * *$ & $0.308 * *$ & $-0.110 * *$ & $0.289 * *$ & $0.236 * *$ & $0.032 *$ \\
\hline sample 2 & $\mathrm{rs}^{6}$ & $0.183 * *$ & $0.286 * *$ & $-0.031 *$ & $0.223 * *$ & $0.293 * *$ & $-0.041 * *$ \\
\hline sample 2 & $\mathrm{rg}^{8}$ & $0.067 * *$ & $0.232 * *$ & $-0.111 * *$ & $0.211 * *$ & $0.160 * *$ & $0.032 *$ \\
\hline sample 3 & $\mathrm{~ms}^{5}$ & $0.234 * *$ & $0.246 * *$ & $0.062 * *$ & $0.345^{* *}$ & $0.321 * *$ & -0.016 \\
\hline sample 3 & $\mathrm{mg}^{7}$ & $0.152 * *$ & $0.207 * *$ & $-0.030 *$ & $0.171 * *$ & $0.160 * *$ & -0.013 \\
\hline sample 3 & $\mathrm{rs}^{6}$ & $0.190 * *$ & $0.295^{* *}$ & $-0.032 *$ & $0.277 * *$ & $0.317 * *$ & $-0.048 * *$ \\
\hline sample 3 & $\mathrm{rg}^{8}$ & $0.109 * *$ & $0.176^{* *}$ & $-0.047 * *$ & $0.142 * *$ & $0.130 * *$ & -0.009 \\
\hline sample 4 & $\mathrm{~ms}^{5}$ & $0.331 * *$ & $0.240 * *$ & $0.073 *$ & $0.235 * *$ & $0.317 * *$ & -0.038 \\
\hline sample 4 & $\mathrm{mg}^{7}$ & $0.163 * *$ & $0.221 * *$ & -0.027 & $0.226 * *$ & $0.162 * *$ & 0.041 \\
\hline sample 4 & $\mathrm{rs}^{6}$ & $0.160 * *$ & $0.284 * *$ & $-0.110 * *$ & $0.194 * *$ & $0.296 * *$ & -0.051 \\
\hline sample 4 & $\operatorname{rg}^{8}$ & $0.127 * *$ & $0.132 * *$ & -0.010 & $0.133 * *$ & $0.112 * *$ & 0.016 \\
\hline sample 5 & $\mathrm{~ms}^{5}$ & $0.255 * *$ & $0.330 * *$ & 0.021 & $0.341 * *$ & $0.389 * *$ & -0.026 \\
\hline sample 5 & $\mathrm{mg}^{7}$ & $0.137 * *$ & $0.347 * *$ & $-0.170 * *$ & $0.310 * *$ & $0.200 * *$ & $0.058 *$ \\
\hline sample 5 & $\mathrm{rs}^{6}$ & $0.151 * *$ & $0.271 * *$ & $-0.097 * *$ & $0.283 * *$ & $0.239 * *$ & 0.022 \\
\hline sample 5 & $\mathrm{rg}^{8}$ & $0.047 *$ & $0.319 * *$ & $-0.224 * *$ & $0.234 * *$ & $0.170 * *$ & 0.034 \\
\hline sample 6 & $\mathrm{~ms}^{5}$ & $0.244 * *$ & $0.277 * *$ & $-0.097 *$ & $0.237 * *$ & $0.381 * *$ & $-0.096^{*}$ \\
\hline sample 6 & $\mathrm{mg}^{7}$ & $0.164 * *$ & $0.354 * *$ & $-0.132 * *$ & $0.211 * *$ & $0.314 * *$ & $-0.072 *$ \\
\hline sample 6 & $\mathrm{rs}^{6}$ & $0.086^{*}$ & $0.331 * *$ & $-0.283 * *$ & $0.228 * *$ & $0.333 * *$ & $-0.073 *$ \\
\hline sample 6 & $\mathrm{rg}^{8}$ & $0.106 * *$ & $0.244 * *$ & $-0.100 *$ & $0.137 * *$ & $0.216 * *$ & -0.057 \\
\hline \multicolumn{2}{|l|}{ Weighted mean } & 0.165 & 0.267 & -0.065 & 0.236 & 0.250 & -0.018 \\
\hline \multicolumn{2}{|l|}{$95 \%$ CI, low } & 0.141 & 0.244 & -0.096 & 0.210 & 0.215 & -0.033 \\
\hline \multicolumn{2}{|l|}{$95 \%$ CI, upp } & 0.189 & 0.290 & -0.033 & 0.262 & 0.284 & -0.003 \\
\hline
\end{tabular}


2021). The used scripts, which also generate the simulated data, are available at the Open Science Framework at https://osf.io/e9nkx/.

\section{Results}

Standardized regression effects of initial intelligence and academic achievement on each other's change between two measurements are presented in Table 1. The effect of initial intelligence on forward change in academic achievement when adjusting for initial academic achievement was uniformly positive, although not very strong (column 1), and similarly for the effect of initial academic achievement on the forward change in intelligence when adjusting for initial intelligence (column 4). This could be seen to suggest that high initial intelligence had a positive facilitating effect on the longitudinal development of academic achievement, and vice versa. However, when predicting change backward in time, the effects remained positive and were slightly stronger (columns 2 and 5). This suggests that given the same subsequent academic achievement (intelligence), those with high initial intelligence (academic achievement) had a higher initial academic achievement (intelligence) and experienced, consequently, a less positive change in academic achievement (intelligence) between the two measurements compared to those with lower initial intelligence (academic achievement). Also the effect of initial intelligence (academic achievement) on the forward change in academic achievement (intelligence) without adjustment for initial academic achievement (intelligence) indicated a negative effect, although somewhat weaker (columns 3 and 6).

The effect of initial intelligence on the change in math scores in $\mathrm{Sa} \beta$ et al.s' sample 2 is illustrated in Figure 2. When predicting forward in time and conditioning on initial math score (in this example the mean), those with high initial intelligence were predicted to have increased more compared with those with average and low initial intelligence (panel A). However, when predicting change backward in time and conditioning on mean subsequent math score, those with high initial intelligence were predicted to have had a higher initial math score and, consequently, to have increased less between the measurements compared with those with average and low initial intelligence (panel B). When not conditioning change on initial math score, those with high initial intelligence were predicted to have had a higher initial math score but not to have increased more (actually slightly, but significantly, less) between the measurements (panel C).

\section{Discussion}

\section{Main findings}

In accordance with predictions and the original studies by Lechner et al. (2019) and $\mathrm{Saß}$ et al. (2021), the present re-analyses found a positive association between initial intelligence and change in academic achievement between two measurements when adjusting for initial academic achievement, and vice versa. However, contrary to predictions, the association between initial intelligence and backward change in academic achievement when adjusting for subsequent academic achievement, and vice versa, remained positive. Also contrary to predictions, the association between initial intelligence and change in academic achievement when not adjusting for initial academic achievement, and vice versa, tended to be negative, although weak. This combination of associations suggest that they are due to regression toward the mean, rather than true facilitating longitudinal effects between intelligence and academic achievement. The observed positive adjusted associations are probably due to a negative association between intelligence (academic achievement) and residual academic achievement (intelligence) when adjusting for observed academic

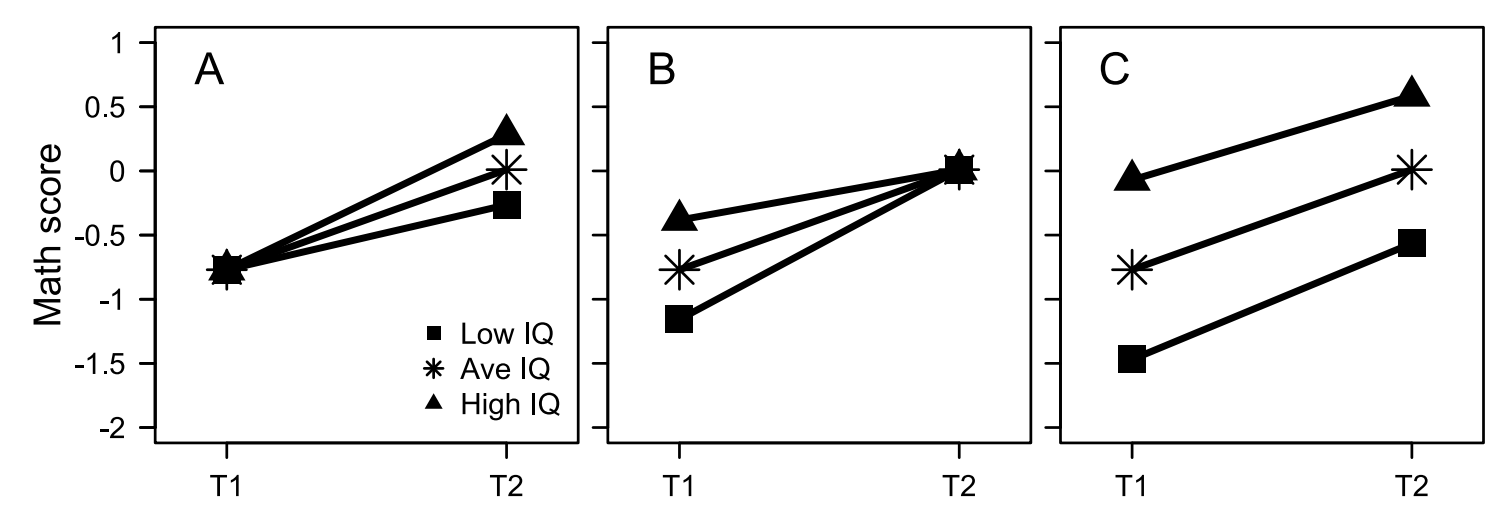

Figure 2. Predicted change in math score between two measurements. Separately for those with low (1 SD below the mean), average, and high ( $1 S D$ above the mean) measured intelligence at the first occasion when predicting forward in time and conditioning on mean initial math score (A), when predicting backward in time and conditioning on mean subsequent math score (B), and when predicting forward in time without conditioning on initial math score (C). 
achievement (intelligence), in combination with a tendency for residuals to regress toward a mean value of zero between measurements.

The phenomenon that the association between $\mathrm{X}$ and the $\mathrm{Y}_{2}-\mathrm{Y}_{1}$ difference can have different signs depending on if adjusted for $\mathrm{Y}_{1}$ or not, has been named Lord's paradox (Lord, 1967). The observed negative unadjusted associations between intelligence and change in academic achievement, and vice versa, in the present study should probably not be seen to indicate that high intelligence (academic achievement) is negative for the longitudinal development of academic achievement (intelligence). Instead, the negative association could be due to a ceiling effect in academic achievement (intelligence) among those with high initial intelligence (academic achievement). Taken together, the findings in the present study should not be seen to suggest a positive, nor a negative, association between initial intelligence and the change in academic achievement between two measurements, or vice versa.

Implications for interpretation of previous research

We do not claim that the present findings generally disprove the existence of facilitating longitudinal effects between intelligence and academic achievement. Rather, our findings call into question the alleged evidence for such effects in Lechner et al. (2019) and Saß et al. (2021). Some studies have included more than two measurements of academic achievement and use individual slopes of academic development as the dependent variable. Results from such analyses should be less susceptible to the influence of regression toward the mean. Some studies employing this methodology have observed (Primi et al., 2010; Williamson et al., 1991) but seemingly at least as many of them have failed to observe (Debatin et al., 2019; Gutman et al., 2003; Johnson et al., 2006; Murayama et al., 2013; Rescorla \& Rosenthal, 2004; XenidouDervou et al., 2018) a positive association between intelligence/general cognitive ability and longitudinal academic development.

\section{Limitations}

The present re-analyses are based on simulated rather than original empirical data. However, the simulated parameters, namely means, variances, and correlations between observed variables, are the crucial ones for results from latent change score models. Consequently, the present findings should be very close to those that would have been obtained if using the original empirical data.

\section{Conclusions}

Observed positive associations between initial intelligence and change in academic achievement between two measurements, and vice versa, when adjusting for the initially observed value on the outcome, may be due to regression toward the mean rather than a true facilitating longitudinal effect. Researchers are recommended to verify observed associations with analyses not adjusting for the initial value on the outcome.

\section{References}

Castro-Schilo, L., \& Grimm, K. J. (2018). Using residualized change versus difference scores for longitudinal research. Journal of Social and Personal Relationships, 35(1), 32-58. https://doi.org/10.1177/0265407517718387

Deary, I. J., Strand, S., Smith, P., \& Fernandes, C. (2007). Intelligence and educational achievement. Intelligence, 35(1), 13-21. https://doi.org/10.1016/j.intell.2006.02.001

Debatin, T., Harder, B., \& Ziegler, A. (2019). Does fluid intelligence facilitate the learning of English as a foreign language?-A longitudinal latent growth curve analysis. Learning and Individual Differences, $70,121-129$. https://doi.org/10.1016/j.lindif.2019.01.009

Eriksson, K., \& Häggström, O. (2014). Lord's paradox in a continuous setting and a regression artifact in numerical cognition research. PLOS ONE, 9(4), e95949. https://doi.org/10.1371/journal.pone.0095949

Galton, F. (1886). Regression towards mediocrity in hereditary stature. The Journal of the Anthropological Institute of Great Britain and Ireland, 15, 246-263. https://doi.org/10.2307/2841583

Ghisletta, P., \& McArdle, J. J. (2012). Latent curve models and latent change score models estimated in R. Structural Equation Modeling: A Multidisciplinary Journal, 19(4), 651-682. https://doi.org/10.1080/10705511.2012.713275

Glymour, M. M., Weuve, J., Berkman, L. F., Kawachi, I., \& Robins, J. M. (2005). When is baseline adjustment useful in analyses of change? An example with education and cognitive change. American Journal of Epidemiology, 162(3), 267-278. https://doi.org/10.1093/aje/kwi187

Gutman, L. M., Sameroff, A. J., \& Cole, R. (2003). Academic growth curve trajectories from 1st grade to 12th grade: Effects of multiple social risk factors and preschool child factors. Developmental Psychology, 39(4), 777-790. https://doi.org/10.1037/00121649.39.4.777

Johnson, W., McGue, M., \& Iacono, W. G. (2006). Genetic and environmental influences on academic achievement trajectories during adolescence. Developmental Psychology, 42(3), 514-532. https://doi.org/10.1037/0012-1649.42.3.514

Kievit, R. A., Brandmaier, A. M., Ziegler, G., van Harmelen, A.-L., de Mooij, S. M. M., Moutoussis, M., Goodyer, I. M., Bullmore, E., Jones, P. B., Fonagy, P., Lindenberger, U., \& Dolan, R. J. (2018). Developmental cognitive neuroscience using latent change score models: A tutorial and applications. Developmental Cognitive Neuroscience, 33, 99-117. https://doi.org/10.1016/j.dcn.2017.11.007

Lechner, C. M., Miyamoto, A., \& Knopf, T. (2019). Should students be smart, curious, or both? Fluid intelligence, openness, and interest co-shape the 
acquisition of reading and math competence. Intelligence, 76, 101378.

https://doi.org/10.1016/j.intell.2019.101378

Lord, F. M. (1967). A paradox in the interpretation of group comparisons. Psychological Bulletin, 68(5), 304-305. https://doi.org/10.1037/h0025105

McArdle, J. J. (2009). Latent variable modeling of differences and changes with longitudinal data. Annual Review of Psychology, 60(1), 577-605. https://doi.org/10.1146/annurev.psych.60.110707.16 3612

Murayama, K., Pekrun, R., Lichtenfeld, S., \& vom Hofe, R. (2013). Predicting long-term growth in students' mathematics achievement: The unique contributions of motivation and cognitive strategies. Child Development, 84(4), 1475-1490. https://doi.org/10.1111/cdev.12036

Pasek, J. (2021). Weights: Weighting and Weighted Statistics. R package version 1.0.4. Https://CRAN.Rproject.org/package $=$ weights.

Peng, P., Wang, T., Wang, C., \& Lin, X. (2019). A metaanalysis on the relation between fluid intelligence and reading/mathematics: Effects of tasks, age, and social economics status. Psychological Bulletin, 145(2), 189-236. https://doi.org/10.1037/bul0000182

Primi, R., Ferrão, M. E., \& Almeida, L. S. (2010). Fluid intelligence as a predictor of learning: A longitudinal multilevel approach applied to math. Learning and Individual Differences, 20(5), 446-451. https://doi.org/10.1016/j.lindif.2010.05.001

$\mathrm{R}$ Core Team. (2021). $R$ : A language and environment for statistical computing. $R$ Foundation for Statistical Computing, Vienna, Austria. URL https://www.Rproject.org/.

Rescorla, L., \& Rosenthal, A. S. (2004). Growth in standardized ability and achievement test scores from 3rd to 10th grade. Journal of Educational Psychology, 96(1), 85-96. https://doi.org/10.1037/0022-0663.96.1.85

Rosseel, Y. (2012). lavaan: An R package for structural equation modeling. Journal of Statistical Software, 48(2), 1-36. https://www.jstatsoft.org/v48/i02/

Roth, B., Becker, N., Romeyke, S., Schäfer, S., Domnick, F., \& Spinath, F. M. (2015). Intelligence and school grades: A metaanalysis. Intelligence, 53, 118-137. https://doi.org/10.1016/j.intell.2015.09.002
Saß, S., Schütte, K., Kampa, N., \& Köller, O. (2021). Continuous time models support the reciprocal relations between academic achievement and fluid intelligence over the course of a school year. Intelligence, 87 , 101560 . https://doi.org/10.1016/j.intell.2021.101560

Sorjonen, K., Melin, B., \& Ingre, M. (2019). Predicting the effect of a predictor when controlling for baseline. Educational and Psychological Measurement, 79(4), 688-698. https://doi.org/10.1177/0013164418822112

Sorjonen, K., Nilsonne, G., \& Melin, B. (2021). Dangers of including outcome at baseline as a covariate in latent change score models [Preprint]. PsyArXiv. https://doi.org/10.31234/osf.io/2sxja

Venables, W. N., \& Ripley, B. D. (2002). Modern applied statistics with $S$ (Fourth Ed.). New York: Springer.

Watkins, M. W., Lei, P.-W., \& Canivez, G. L. (2007). Psychometric intelligence and achievement: A cross-lagged panel analysis. Intelligence, 35(1), 59-68. https://doi.org/10.1016/j.intell.2006.04.005

Watkins, M. W., \& Styck, K. (2017). A crosslagged panel analysis of psychometric intelligence and achievement in reading and math. Journal of Intelligence, 5(3), 31. https://doi.org/10.3390/jintelligence5030031

Williamson, G. L., Appelbaum, M., \& Epanchin, A. (1991). Longitudinal analyses of academic achievement. Journal of Educational Measurement, 28(1), 61-76. https://doi.org/10.1111/j.17453984.1991.tb00344.x

Xenidou-Dervou, I., Van Luit, J. E. H., Kroesbergen, E. H., Friso-van den Bos, I., Jonkman, L. M., van der Schoot, M., \& van Lieshout, E. C. D. M. (2018). Cognitive predictors of children's development in mathematics achievement: A latent growth modeling approach. Developmental Science, 21(6), e12671. https://doi.org/10.1111/desc.12671 